\title{
Pregnant mother's knowledge level and its determinant factors towards preventable risk factors of congenital anomalies among mothers attended health institutions for antenatal care, Ethiopia
}

\author{
Getu Engida wake ${ }^{a, *}$, Girma Wogie Fitie ${ }^{a}$, Seada Endris ${ }^{b}$, Shiferaw Abeway ${ }^{\text {, }}$, \\ Gebremaryam Temesgen ${ }^{c}$ \\ ${ }^{a}$ Department of Midwifery, Institute of Medicine and Health Science, Debre Berhan University, Debre Berhan, Ethiopia \\ ${ }^{\mathrm{b}}$ School of Nursing and Midwifery, Department of Midwifery, College of Medicine and Health Science, Wollo University, Dessie, Ethiopia \\ ${ }^{\mathrm{c}}$ Department of Midwifery, College of Medicine and Health Science, Arbaminch University, Arbaminch, Ethiopia
}

\section{A R T I C L E I N F O}

\section{Keywords:}

Anomalies

Congenital

Deformities

Ethiopia

Knowledge

\begin{abstract}
A B S T R A C T
Background: More than $90 \%$ of congenital anomalies occur in low and middle-income countries because of different risk factors. This study aimed to assess pregnant mothers' knowledge level and its determinant factors towards preventable risk factors of congenital anomalies among mothers attended health institutions for antenatal care in Dessie town, Ethiopia.

Methods: Health institution-based cross-sectional study design was conducted among 404 pregnant mothers in Dessie town, Ethiopia from 12 January 2020 to 12 March 2020. A systematic random sampling method was used to get selected mothers. Epidata version 3.1 and, and SPSS version 20 were used for data entry and analysis respectively.

Results: A total of 404 pregnant mothers were included with a $100 \%$ response rate. The overall good knowledge of pregnant mothers towards preventable risk factors of congenital anomalies was $211(52 \%)$.Four or more antenatal care visits [adjusted OR $=2.93,95 \%$ CI: $1.696-5.072, \mathrm{P}$-value $<0.001$ ], urban residence [ adjusted OR $=5.97,95 \%$ CI: 2.95-12.078,P-value $<0.001$ ], monthly family income of more than 4500 ETB [adjusted OR = 5.52, 95\% CI: 1.616-18.861,P-value <0.006] and secondary school and above [adjusted OR $=4.29$, 95\%CI: 2.464-7.467, P- value $<0.001$ ] were significant associated factors with pregnant mothers knowledge.

Conclusion: More than half of pregnant mothers had good knowledge of preventable risk factors of congenital malformation. Governmental and non-governmental health institutions should create a conducive environment for health care providers to create awareness regarding preventable risk factors of congenital malformation for all couples, pregnant mothers, and the community as a whole.
\end{abstract}

\section{Introduction}

The world health organization (WHO) defined congenital anomalies as birth defects, which can be structural or functional abnormalities, including metabolic disorders, that are present from birth. ${ }^{1,2}$ Globally, the prevalence of congenital anomaly varies from region to region, and evidence indicated that in the United States of America (USA) the prevalence of congenital malformation was 28.9 per 1000 live births. ${ }^{3}$ According to the report of data from the EUROCAT registry of the
County of Funen Denmark, the overall prevalence of multiple congenital anomalies during the years $1990-2014$ was 19.7 per 10,000 birth$\mathrm{s} .{ }^{4}$ Again the prevalence of birth defects among newborn infants in sub-Saharan African countries varies widely and it accounts for $9.17 / 1000$ in western African countries and 43/1000 in southern Africa. ${ }^{5}$

Although, congenital anomalies are a serious cause of infant mortality and morbidity for both developed and developing countries, more than $90 \%$ of birth defects and about $95 \%$ of infant mortality occurred in

Abbreviations: ANC, antenatal care; AOR, adjusted odds ratio; CI, confidence interval; ETB, Ethiopian Birr; LMIC, low and middle-income countries; OR, odds ratio; SPSS, Statistical Package for Social Sciences; USA, Unites State of America; WHO, World health organization.

* Corresponding author.

E-mail addresses: getuengida2023@gmail.com (G.E. wake),wogiegirma@gmail.com (G.W. Fitie), seadaendris26@gmail.com (S. Endris), shifeby@gmail.com (S. Abeway), degnesh31@gmail.com (G. Temesgen). 
low and middle-income countries (LMICs).$^{6,7}$ Not only in developing countries but also congenital anomalies accounts for about 208.55/100, 000 cases of hospital admission during 2019 in European countries. ${ }^{8}$ According to a 2015 world health organization report, globally 276,000 newborns under one month of age died as a result of congenital anomalies. ${ }^{9}$ In addition, birth defects were risk factors for the death of 303, 000 neonates within a month of delivery and 3.2 million disabilities for live-born children with a direct impact on children, families, health care systems, and communities. ${ }^{10}$ Although exact causes have not yet been identified for most congenital anomalies, environmental and genetic factors are the cause of some birth defects. ${ }^{11,12}$ In developing countries, maternal infection with Rubella and Syphilis were identified as the common causes of birth defects. ${ }^{13}$ Another evidence suggested that the causes of some congenital anomalies can be related to multifactorial origins $^{14-16}$ and environmental factors. ${ }^{17,18}$ Because of these, investigating the underlining causes and risk factors of congenital anomalies may help to decrease the incidence of birth defects which is related to preventable risk factors of congenital anomalies and at present, vaccination, dietary intake of folate or iodine, preconception health care and ultrasound evaluation during pregnancy are available options for prevention of some form of birth defect. ${ }^{19-21}$

Similar to developing countries, the prevalence of congenital anomalies in Ethiopia is also raising. Evidence showed that the proportion of birth defects in Ethiopia ranges from 1.14\% during 2010 to $2.83 \%$ in $2014 .{ }^{22}$ Another studies conducted in Ethiopia showed that the prevalence of congenital anomaly ranges from $1.61 \%{ }^{23}$ to $1.99 \%{ }^{14}$ and congenital malformation is one of the direct causes of under-five mortality(4\%) in Ethiopia. ${ }^{24}$ Even though congenital anomalies have a great impact on neonatal mortality, morbidity, the social and economic burden of the family, to the best of the authors' knowledge no previous study investigated the pregnant mothers' knowledge towards preventable risk factors of congenital anomaly in Ethiopia. So this study aimed to assess the knowledge level of pregnant mothers towards preventable risk factors of congenital anomaly and associated factors with their knowledge among mothers who attended their antenatal care at governmental and private health institutions in Dessie town 2020. The finding of this study will be used as a baseline for other studies as well as for planning primary prevention modalities for preventable congenital anomalies and to reduce neonatal mortality, morbidity, and the incidence of congenital anomalies.

\section{Methods}

\subsection{Study design}

An institutional-based cross-sectional study was conducted from 12 January 2020 to 12 March 2020.

\subsection{Study setting and study participants}

Dessie town is the capital city of the South Wollo zone of Amhara regional state, which is located $401 \mathrm{~km}$ away from Addis Ababa city. There are four governmental health institutions and three private health institutions in Dessie town that provide maternal and child health services and we included all governmental and private health institutions in the town. Pregnant women who came to attend antenatal care at governmental and private health institutions in Dessie town during the study period were our study population.

\subsection{Inclusion and exclusion criteria}

All pregnant mothers who attended antenatal care services at governmental and private health institutions in Dessie town during the data collection period were included, while Pregnant mothers who were seriously sick and unable to respond during the data collection time were excluded from the study.

\subsection{Sample size determination, sampling technique, and procedure}

The sample size for the outcome variable was determined using a single population proportions formula as follows.

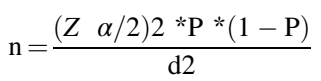

where;

$\mathrm{n}=$ the actual sample size

$\mathrm{Z}=$ the standard normal deviation at $95 \%$ confidence interval; =

1.96

$\mathrm{P}=$ proportion of knowledge

$\mathrm{d}=$ margin of error that can be tolerated, $5 \%(0.05)$

Therefore $\mathrm{P}$ is the proportion of knowledge about congenital anomaly $=48.1 \%$, taken from a study conducted in Ghana. ${ }^{25}$

$1-\mathrm{p}=0.519$

$\mathrm{n}=\frac{(1.96) 2 * 0.481 * 0.519}{(0.05) 2}=383.6=384$

By considering a $5 \%$ of non-response rate $(n=20$, the final sample size becomes $(\mathrm{N}=404)$ pregnant mothers.

\subsection{Sampling technique and procedure}

There are a total of seven health institutions in Dessie town that provides maternal and child health services. From these, 4 health institutions were governmental (one referral hospital and three health centers) and the remaining 3 hospitals were private health institutions. The numbers of pregnant mothers who visited health institutions that were surveyed from each health institution were allocated proportionally. The estimation was made depending on the number of pregnant mothers who visited each health institution for the last 2 months. The proportional allocation was calculated using the following formula:

$\mathrm{nj}=\mathrm{n} / \mathrm{N}^{*} \mathrm{Nj}$

Where:

$\mathrm{nj}=$ Sample size of the $\mathrm{jth}$ health institution

$\mathrm{n}=$ Total sample size

$\mathrm{Nj}=$ Number of pregnant mothers who visited the jth health institution in the last 2months.

$\mathrm{N}=$ Total number of pregnant mothers who visited all health institutions in the last 2 months.

Lastly, study participants were selected systematically $(k=4)$ based on the order of pregnant mothers who come to the antenatal care room at health institutions until the required sample size was obtained (Fig. 1).

\subsection{Operational definition}

Good knowledge: A total of 10 knowledge assessing questions were used and study participants who answered equal to or greater than the mean values of knowledge-related questions were categorized as good in knowledge.

Poor knowledge: Study participants who answered less than the mean values of knowledge-related questions.

Preventable risks of a congenital anomaly: Are risks factors that can be prevented by food fortifications, supplementation of micronutrients, and avoiding risky behavior like alcohol consumption, cigarette smoking, and some drugs during pregnancy. 


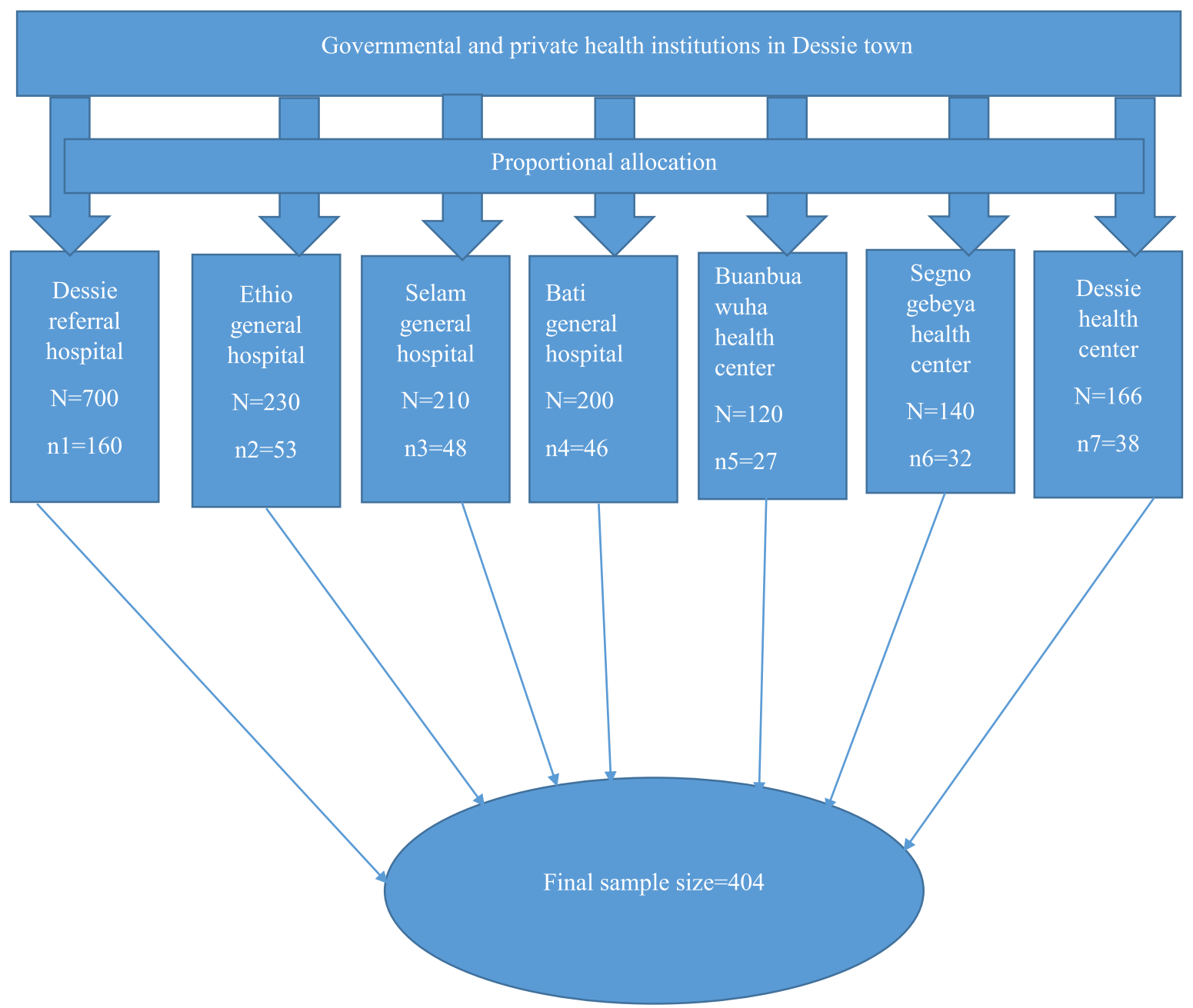

Fig. 1. Schematic presentation of sampling procedure of the study.

\subsection{Methods of data collection tool, procedure, and quality control}

Data were collected by face-to-face interview administered structured questionnaire and all required data was collected by four trained degree midwives who were working in maternal and child health unit of governmental and private health institutions in Dessie town. The questionnaires which were adopted and adapted from different literature were designed in the English language, translated into the local language (Amharic), and back to the English language for consistency of collected data. These questionnaires consist of three parts: the first part was used to assess socio-demographic and obstetrics characteristics of pregnant women and the second part was used to assess factors associated with pregnant mothers' knowledge towards preventable risk factors of congenital anomalies. The third part which was an open-ended questionnaire was used to collect data on the participant's perceptions concerning the causes of congenital malformations.

To maintain data quality, four-degree midwives were given training of one day about data collection procedures, tools, and how to fill data. In addition, the questionnaire was pre-tested in $5 \%$ of the sample size in Akesita hospital three weeks before the actual data collection period, and necessary amendments such as language clarity and appropriateness of the tools were done based on the findings of the pretest before the actual data collection time. Daily close supervision at the end of each day was made, collected data was reviewed and checked for completeness and consistency by supervisors and principal investigator.

\subsection{Data processing and analysis}

The collected data were cleaned manually for completeness and any misfiled questions were corrected and coded before entry. Then coded data were entered into Epidata version 3.1 and exported to SPSS version 22.0 for analysis. Descriptive statistics (mean, median, standard deviation, and percentage) were used to summarize the data. Binary logistic regression was used to identify the association between pregnant mothers' knowledge towards preventable risk factors of congenital anomaly and other independent variables. Variables with a significant association in the bivariate analysis were entered into multivariate analysis to assess the significance. $P$-values less than 0.2 and 0.05 were considered statistically significant for bivariate and multivariate regression, respectively, and the whole results were presented in texts, tables, and figures. Hosmer-Lemeshow's test was found insignificant (pvalue $=0.593$ ) and the omnibus test was significant ( $\mathrm{p}$-value $=0.000)$ which indicated model fitness.

\section{Results}

\subsection{Socio-demographic characteristics of the study participants}

A total of 404 pregnant mothers were involved with a response rate of $100 \%$. From the total study participants, nearly half (47.3\%) of them were Muslim religion followers and the age ranges of the study participants were between 18 and 43 years with a mean age of 28.7 years. Less than half (42.6\%) of study participants had primary school educational 
levels. Regarding the residence of pregnant mothers, more than half $(71.8 \%)$ of them were from urban, almost all of them (95.5\%) were married, and more than half $(60.1 \%)$ of them were housewives (Table 1).

\subsection{Obstetrics characteristics}

Regarding parity of the study participants more than half (60.9\%) of them were multipara and the majority of them $(84.2 \%)$ were multigravida. Concerning antenatal care (ANC) visit number, more than half (60.9\%) of them made less than 4 ANC visits and 152(37.6\%) of study participants took their ANC service from the health center for the previous pregnancy. Regarding the history of the presence of a congenital anomaly in the family, $12(3 \%)$ of pregnant mothers had a previous history of a child with a congenital anomaly (Table 2).

\subsection{Knowledge of pregnant mothers towards preventable risk factors of congenital anomalies}

From the total study participants included $(N=404)$, nearly more than half of them 211(52.2\%) were good in knowledge towards preventable risk factors of congenital anomalies and 193(47.8\%) had poor knowledge of preventable risk factors of congenital malformation (Fig. 2). The majority of study participants (68.6\%) knew that congenital anomalies are not transmitted through contact with affected individuals. From total study participants, 280(69.3\%) and 156(38.6\%) of them knew that the use of some un-prescribed medications and alcohol consumption during pregnancy causes congenital malformation respectively. Nearly half of the study participants (47.8\%) had information about congenital anomalies due to smoking before and during pregnancy. Regarding maternal infection during pregnancy less than half $(42.1 \%)$ of them reported that maternal infection during pregnancy increases the risk of giving birth to a child with congenital anomalies. More than half of study participants(61.4\%) were identified consumption of folic acid before or during pregnancy can minimize the incidence of congenital malformation and 225(55.7\%) were identified that regular checkups throughout the pregnancy time decrease the risk of having a child with congenital anomaly(Table 3). Based on pregnant mothers' perception regarding the cause of congenital malformation, nearly half

Table 1

Distribution of pregnant mothers by socio-demographic characteristics at governmental, and private health institutions in Dessie town $(n=404)$.

\begin{tabular}{llll}
\hline variables & category & frequency & percentage \\
\hline Age & $\leq 19$ year & 8 & 2.0 \\
& 20-24 year & 78 & 19.3 \\
25-29 year & 153 & 37.9 \\
30-34 year & 105 & 26.0 \\
35-39 year & 44 & 10.8 \\
Ethnicity & 40-49 year & 16 & 4.0 \\
& Amara & 338 & 83.7 \\
Level of education & Oromo & 38 & 9.4 \\
& Tigray & 19 & 4.7 \\
& Afar & 9 & 2.2 \\
& Unable to read and write & 40 & 9.9 \\
& Primary school & 172 & 42.6 \\
Monthly family income & Secondary school & 128 & 31.7 \\
& College and above & 64 & 15.8 \\
& $\leq 1500$ & 53 & 13.1 \\
& 1501-3000 & 191 & 47.2 \\
& 3001-4500 & 113 & 27.9 \\
Occupation & >4500 & 47 & 11.6 \\
& Housewife & 243 & 60.1 \\
& Merchant & 60 & 14.9 \\
& Private organization & 34 & 8.4 \\
& Government employee & 30 & 7.4 \\
& Daily labor & 33 & 8.2 \\
& Other & 4 & 1.0 \\
\hline \multirow{5}{*}{ a } & & &
\end{tabular}

a Students.
Table 2

Pregnant mothers' obstetrics characteristics at governmental and private health institutions in Dessie town $(n=404)$.

\begin{tabular}{llll}
\hline Variable & category & Frequency & Percentage \\
\hline Parity & Primipara & 158 & 39.1 \\
& Multipara & 246 & 60.9 \\
Gravida & Primigravida & 64 & 15.8 \\
\multirow{2}{*}{ Number of ANC visits } & Multigravida & 340 & 84.2 \\
& Less than 4 ANC & 246 & 60.9 \\
& visits & & \\
& 4 and above ANC & 158 & 39.1 \\
Children with congenital & visits & & \\
anomalies in the family & Yes & 12 & 3.0 \\
Place of ANC visit in the previous & No & 392 & 97.0 \\
pregnancy & Health center & 152 & 37.6 \\
& Primary hospital & 62 & 15.3 \\
& General hospital & 66 & 16.3 \\
& Referral hospital & 59 & 14.6 \\
& No ANC visit & 65 & 16.1 \\
\hline
\end{tabular}

Key-px- pregnancy, CA-congenital anomalies.

of the study participants(52.7\%) were perceived that congenital anomaly was caused by supernatural factors, and 62(15.3\%) of pregnant mothers believed eating some forbidden foods during pregnancy can cause the congenital anomaly. Only $13(3.2 \%)$ of the study participants perceived that a mothers were likely to have an affected child if she gives birth to too many children (Fig. 3).

\subsection{Factors associated with the knowledge of the preventable risk of congenital anomalies}

Bivariate and multivariate logistic regression was conducted to examine the association between pregnant mothers' knowledge towards preventable risk factors of congenital anomalies and its associated factors. In bivariate logistic regression analysis variables like; age, marital status, educational level, residence, gravidity, monthly income of the family, number of ANC visit, place of ANC follow-up in the previous pregnancy was significantly associated with pregnant mothers knowledge of a preventable risk of congenital anomalies. On multivariate logistic regression analysis, four variables (repeated antenatal care visits, participant residence, and monthly income of the family, and educational level of study participants) were significantly associated with the knowledge level of pregnant mothers towards preventable risk factors of congenital anomalies. Those pregnant mothers who had attended four or more antenatal care visits were almost 3 times more likely to have good knowledge towards preventable risk factors of congenital anomalies than mothers who had an experience of less than four ANC visits [AOR $=2.93$, 95\% CI:1.696-5.072]. Those pregnant mothers who lived in urban were 6 times more likely to have good knowledge of preventable risk factors of congenital anomalies compared to those mothers who were living in rural areas [AOR $=5.97,95 \%$ CI:2.95-12.078]. Those pregnant mothers who had a monthly family income of more than 4500 Ethiopian Birr(ETB) were almost 6 times more likely to have good knowledge towards preventable risk factors of congenital anomalies when compared to those pregnant mothers who had a monthly family income of less than 1500 Ethiopian Birr(ETB)[AOR $=5.52,95 \% \mathrm{CI}$ : 1.616-18.861]. Moreover, those pregnant mothers who had an educational level of secondary school and above were 4.3 times more likely to have good knowledge towards preventable risk factors of congenital anomalies when compared to pregnant mothers who had below secondary educational level[AOR = 4.29, 95\%CI: 2.464-7.467](Table 4).

\section{Discussion}

This study aimed to assess pregnant mothers' knowledge towards preventable risk factors of congenital malformation and associated factors towards their knowledge level among mothers who attended 


\section{knowledge level of pregnant mothers towards prevantable risk factors of congenital anomalies}

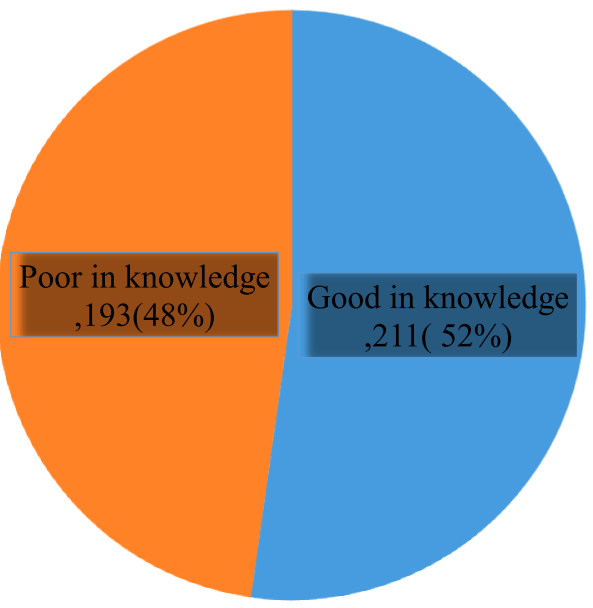

- Poor in knowledge

Good in knowledge

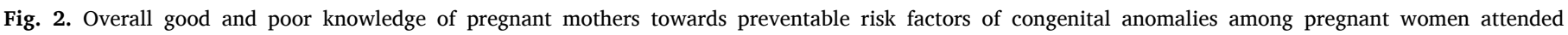
governmental and private health institutions in Dessie town, Ethiopia, 2020.

Table 3

Level of knowledge among study participants on the preventable risk of congenital anomalies at governmental and private health institutions in Dessie town $(\mathrm{n}=404)$.

\begin{tabular}{|c|c|c|c|}
\hline Variables & $\begin{array}{l}\text { YES } n \\
(\%)\end{array}$ & $\begin{array}{l}\text { NO } n \\
(\%)\end{array}$ & $\begin{array}{l}\text { Don't know } n \\
(\%)\end{array}$ \\
\hline $\begin{array}{l}\text { Risk factors } \\
\text { It can be transmitted by contact with } \\
\text { affected } \\
\text { Individuals }\end{array}$ & $51(12.6)$ & $\begin{array}{l}277 \\
(68.6)\end{array}$ & $76(18.8)$ \\
\hline Congenital anomalies are preventable & $\begin{array}{l}115 \\
(28.5)\end{array}$ & $\begin{array}{l}130 \\
(32.2)\end{array}$ & $159(39.4)$ \\
\hline Alcohol consumption during pregnancy & $\begin{array}{l}156 \\
(38.6)\end{array}$ & $\begin{array}{l}132 \\
(32.7)\end{array}$ & $116(28.7)$ \\
\hline Use of some un-prescribed medications & $\begin{array}{l}280 \\
(69.3)\end{array}$ & $\begin{array}{l}63 \\
(15.6)\end{array}$ & $61(15.1)$ \\
\hline Smoking before and during pregnancy & $\begin{array}{l}193 \\
(47.8)\end{array}$ & $\begin{array}{l}90 \\
(22.3)\end{array}$ & $121(30.0)$ \\
\hline Advanced maternal age ( $\geq 40$ years) & $90(22.3)$ & $\begin{array}{l}191 \\
(47.3)\end{array}$ & $123(30.4)$ \\
\hline Maternal infection during pregnancy & $\begin{array}{l}170 \\
(42.1)\end{array}$ & $\begin{array}{l}124 \\
(30.7)\end{array}$ & $110(27.2)$ \\
\hline \multicolumn{4}{|l|}{ Prevention } \\
\hline $\begin{array}{l}\text { Consumption of iodized salt during } \\
\text { pregnancy }\end{array}$ & $93(23.0)$ & $\begin{array}{l}208 \\
(51.5)\end{array}$ & $103(25.5)$ \\
\hline $\begin{array}{l}\text { Consumption of folic acid before and } \\
\text { during pregnancy }\end{array}$ & $\begin{array}{l}248 \\
(61.4)\end{array}$ & $\begin{array}{l}51 \\
(12.6)\end{array}$ & $105(26.0)$ \\
\hline $\begin{array}{l}\text { Regular checkups throughout the } \\
\text { pregnancy period }\end{array}$ & $\begin{array}{l}225 \\
(55.7)\end{array}$ & $\begin{array}{l}81 \\
(20.0)\end{array}$ & $98(24.3)$ \\
\hline
\end{tabular}

their antenatal care visit at health institutions in Dessie town Amhara region, Ethiopia. This study found that over half of pregnant women 211 (52\%) had good knowledge of preventable risk factors of congenital anomalies. This finding is in line with the result of a study conducted in Sri Lanka (56\%). ${ }^{26}$ But it is lower than the finding of the study conducted in Egypt (76\%). ${ }^{27}$ This difference might be due to differences in the study area where data was collected. Necessary information was gathered from only one referral hospital in Cairo compared to our study where pregnant mothers from health centers and hospitals were included. Again this difference might be related to the presence of health information dissemination regarding genetic counseling services in Egypt for women in the reproductive age group contrary to our study. ${ }^{28}$ In addition, this finding is lower than the finding of a study conducted in Srilanka (73.3\%) $)^{29}$ and India(63.5\%). ${ }^{30}$ This difference might be related to the difference in Socio-demographic status, the cultural difference of study participants, sample size, sampling methods, and the number and types of health institutions from which the data was collected. However, this finding is higher than the report of the study conducted in Ghana (42\%), Nigeria (25.6\%), Egypt (20.1\%), and Northern Iran (32\%) respectively. ${ }^{25,31-33}$ This difference might be related to methodological difference (study population, study design), dissimilarity of socio-cultural characteristics of study participants, and difference in a time lag. The study conducted in Egypt was a community-based study which was undertaken in a rural area where there might be a lack of awareness towards risk factors of congenital malformation compared to our study which was a health institution-based study and this might bring the difference.

Repeated number of antenatal care visits, educational level, participant's residence, and monthly income of the family were determinant factors of pregnant mother knowledge towards preventable risk factors of congenital anomalies. Those Pregnant mothers who attended four and above antenatal care visits were 3 times more likely to have a good knowledge than mothers who had an experience of less than four ANC visits. This finding is in line with the finding of a study conducted in Sri Lanka and India. ${ }^{26,30}$ This might be related to repeated health facility visits for antenatal care increase maternal contact with skilled health professionals, and enabled them to upgrade their awareness towards preventable risk factors of congenital anomalies. But the finding of this study regarding the association of the number of antenatal care with maternal knowledge is different from the result of the study conducted in Ghana ${ }^{25}$ which reported the absence of any association between the number of antenatal care visits and knowledge level of pregnant mothers. This difference might be because of the difference in coverage of topics discussed with pregnant mothers during antenatal care sessions and the nature of health institutions providing antenatal care in the study area. Those pregnant mothers who had an educational status of secondary school and above were 4 times more likely to have good knowledge of a preventable risk of congenital anomalies compared to mothers who had less than secondary school. This finding is in line with the results of the study conducted in Sri Lanka, Egypt, Nigeria, Egypt, and North of Iran. ${ }^{26,27,31-33}$ Probably those mothers who were at a higher educational level were read, watch, and listen to different material and media regarding preventable risk factors of congenital anomalies and upgrade their knowledge, and developed good healthcare-seeking behavior. Evidence suggested that a higher formal education level was associated with the utilization of modern health care among pregnant mothers. ${ }^{11,34}$ Pregnant mothers who lived in urban areas were 6 times more likely to have good knowledge towards 


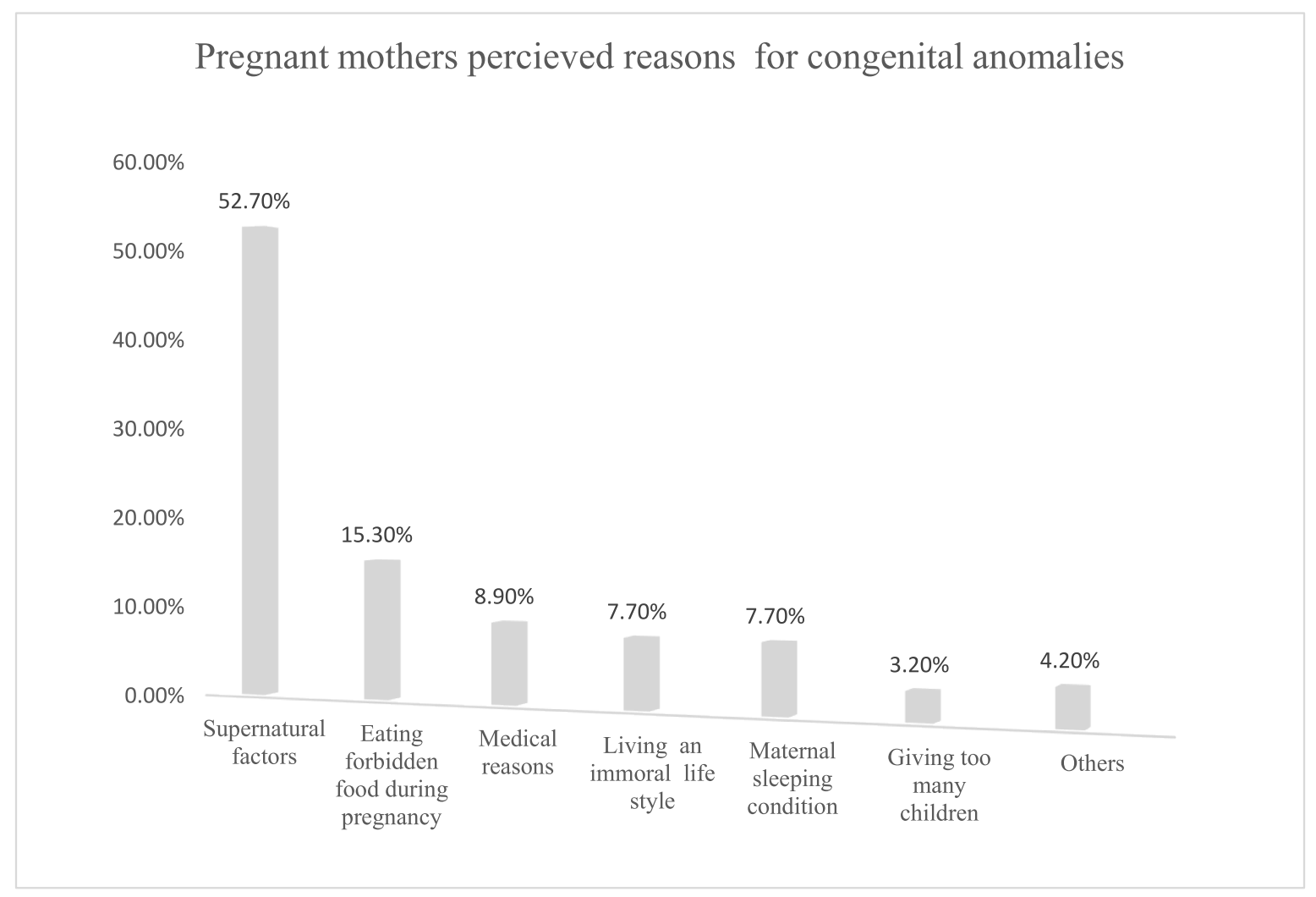

Fig. 3. Perceived reasons for the cause of congenital anomalies among pregnant women attended governmental and private health institutions in Dessie town, Ethiopia, 2020.

preventable risk factors of congenital anomalies than their counterparts. This finding is similar with the report of the study conducted in India. ${ }^{30}$ This might be due to that urban-dwelling mothers had access to different sources of information from media and expert personals regarding preventable risk factors of congenital anomalies. Besides, some evidence suggested that women in developed regions, residing in the urban area, educated women and wealthier use health service care effectively than their counterparts. ${ }^{35,36}$ Again this study showed that pregnant mothers who had higher monthly family income (greater than 4500 Ethiopian Birr) were 6 times more likely to have good knowledge towards preventable risk factors of congenital anomalies than those pregnant mothers with a monthly family income of less than 1500 ETB. This finding is in line with the result of the study conducted in Sri Lanka and India. ${ }^{26,30}$ Those pregnant mothers who had higher family income might have full access to get health-related information from radio, television, and social media than those with lower family income and this might be the cause of this difference.

\section{Limitation of the study}

The cause and effect relationship of the predictor variables with the level of pregnant mother knowledge is not determined because of the cross-sectional nature of the study design. Besides, the absence of another study conducted in Ethiopia on this topic makes it difficult for authors to make compare and contrast in the discussion part of the study. The power of generalizability of this study is relatively low since the study population of our study was only pregnant mothers who attended health institutions of Dessie town, Ethiopia.

\section{Conclusion}

The study found that over half of women had good knowledge of preventable risk factors of congenital anomalies. Furthermore, the results of this study showed that repeated number of antenatal care visits, Educational level, participant's residence, and higher monthly income of the family were identified as major determinants of pregnant mother's knowledge towards preventable risk factors of congenital anomalies. Governmental and non-governmental health institutions should create a conducive environment for health care providers to create awareness regarding preventable risk factors of congenital malformation for couples. Policymakers should integrate preconception care services into primary health care services and begin providing preconception care services at all health institution levels in Ethiopia. Health care professionals should provide preconception health education, and create adequate awareness regarding cause and prevention methods of preventable risk factors of birth defects giving special attention for those pregnant mothers who were in low socioeconomic status, pregnant mothers from the rural area and pregnant mothers with low educational status, in addition to all women in reproductive age group, couples, and community as a whole.

\section{Data sharing statement}

All datasets used for this study are available from the corresponding author on request.

\section{Ethics approval}

Ethical clearance was obtained from the research and ethical review board of Mekelle University, college of health sciences. The letter of permission from the ethical review board and Midwifery department was submitted to all governmental and private health institutions in Dessie town. Besides, a letter of permission which was obtained from all seven governmental and private health institutions in Dessie town was submitted to each health institution's maternal and child health unit department. Lastly, informed written consent was obtained from 
Table 4

Bivariate and multivariable analysis factors that associated with knowledge on preventable risks of congenital anomalies among pregnant mothers at governmental and private health institutions in Dessie town $(n=404)$.

\begin{tabular}{|c|c|c|c|c|c|}
\hline \multirow[t]{2}{*}{ Variables } & \multicolumn{2}{|c|}{$\begin{array}{l}\text { Knowledge } \\
\text { of } \\
\text { congenital } \\
\text { anomalies }\end{array}$} & \multirow[t]{2}{*}{ COR $(95 \% \mathrm{CI})$} & \multirow[t]{2}{*}{ AOR $(95 \% \mathrm{CI})$} & \multirow[t]{2}{*}{ P-value } \\
\hline & Yes & No & & & \\
\hline \multicolumn{6}{|l|}{ Age category } \\
\hline$\leq 24$ year & 33 & 53 & 1 & 1 & \\
\hline $25-29$ year & $\begin{array}{l}1 \\
01\end{array}$ & 52 & $\begin{array}{l}3.119 \\
(1.803,5.398)\end{array}$ & $\begin{array}{l}2.12 \\
(0.985,4.558)\end{array}$ & 0.055 \\
\hline 30-34year & 48 & 57 & $\begin{array}{l}1.352 \\
(0.757,2.415)\end{array}$ & $\begin{array}{l}0.96 \\
(0.401,2.313)\end{array}$ & 0.93 \\
\hline $35-39$ & 23 & 21 & $\begin{array}{l}1.759 \\
(0.844,3.665)\end{array}$ & $\begin{array}{l}2.14 \\
(0.753,6.076)\end{array}$ & 0.15 \\
\hline above 40 year & 6 & 10 & $\begin{array}{l}0.964 \\
(0.320,2.899)\end{array}$ & $\begin{array}{l}1.61 \\
(0.398,6.428)\end{array}$ & 0.51 \\
\hline \multicolumn{6}{|l|}{ Marital status } \\
\hline Married & 206 & 180 & $\begin{array}{l}2.98 \\
(1.041,8.508)\end{array}$ & $\begin{array}{l}0.43 \\
(0.112,1.656)\end{array}$ & 0.22 \\
\hline $\begin{array}{l}\text { Unmarried } \\
\text { Residence }\end{array}$ & 5 & 13 & 1 & 1 & \\
\hline Urban & 191 & 99 & $\begin{array}{l}9.07 \\
(5.283,15.564)\end{array}$ & $\begin{array}{l}5.97 \\
(2.951,12.078)\end{array}$ & $<0.001 *$ \\
\hline Rural & 20 & 94 & 1 & 1 & \\
\hline \multicolumn{6}{|c|}{ Educational status } \\
\hline $\begin{array}{l}\text { Below } \\
\text { secondary }\end{array}$ & 65 & 147 & 1 & 1 & \\
\hline $\begin{array}{l}\text { Secondary\& } \\
\text { above }\end{array}$ & 146 & 46 & $\begin{array}{l}7.18 \\
(4.615,11.16)\end{array}$ & $\begin{array}{l}4.29 \\
(2.464,7.467)\end{array}$ & $<0.001 *$ \\
\hline \multicolumn{6}{|c|}{ Monthly family income } \\
\hline$\leq 1500$ & 14 & 39 & 1 & 1 & \\
\hline $1501-3000$ & 71 & 120 & $\begin{array}{l}1.648 \\
(0.837,3.245)\end{array}$ & $\begin{array}{l}1.17 \\
(0.486,2.828)\end{array}$ & 0.723 \\
\hline $3001-4500$ & 87 & 26 & $\begin{array}{l}9.32 \\
(4.396,19.764)\end{array}$ & $\begin{array}{l}2.87 \\
(1.103,7.454)\end{array}$ & $0.031 *$ \\
\hline$>4500$ & 39 & 8 & $\begin{array}{l}13.58 \\
(5.120,36.02)\end{array}$ & $\begin{array}{l}5.52 \\
(1.616,18.861)\end{array}$ & $<0.006$ \\
\hline \multicolumn{6}{|l|}{ Gravida } \\
\hline Primigravida & 26 & 38 & 1 & 1 & \\
\hline Multigravida & 185 & 155 & $\begin{array}{l}1.74 \\
(1.014,3.001)\end{array}$ & $0.000(000)$ & 0.99 \\
\hline \multicolumn{6}{|c|}{ Number of ANC visit } \\
\hline $\begin{array}{l}\text { Less than } \\
\text { 4ANC }\end{array}$ & 92 & 154 & 1 & 1 & \\
\hline $4 \&$ above ANC & 119 & 39 & $\begin{array}{l}5.11 \\
(3.275,7.965)\end{array}$ & $\begin{array}{l}2.93 \\
(1.696,5.072)\end{array}$ & $<0.001 *$ \\
\hline \multicolumn{6}{|c|}{ Place of previous ANC } \\
\hline Health center & 76 & 76 & 1 & 1 & \\
\hline $\begin{array}{l}\text { Primary } \\
\text { hospital }\end{array}$ & 34 & 28 & $\begin{array}{l}1.21 \\
(0.671,0.964)\end{array}$ & $\begin{array}{l}0.92 \\
(0.423,1.986)\end{array}$ & 0.83 \\
\hline $\begin{array}{l}\text { General } \\
\text { hospital }\end{array}$ & 43 & 23 & $\begin{array}{l}1.87 \\
(1.028,3.399)\end{array}$ & $\begin{array}{l}1.01 \\
(0.439,2.283)\end{array}$ & 0.99 \\
\hline $\begin{array}{l}\text { Referral } \\
\text { hospital }\end{array}$ & 34 & 25 & $\begin{array}{l}1.36 \\
(1.001,2.494)\end{array}$ & $\begin{array}{l}0.84 \\
(0.363,1.961)\end{array}$ & 0.69 \\
\hline No ANC visits & 24 & 41 & $\begin{array}{l}0.58 \\
(0.323,1.062)\end{array}$ & $0.000(000)$ & 0.99 \\
\hline
\end{tabular}

Keywords: *P $<0.05$ has a significant association, COR-crud Odds ratio, AORAdjusted odds ratio.

pregnant mothers before data collection after information about the study was provided.

\section{Funding}

This research did not receive any specific grant from funding agencies in the public, commercial, or not-for-profit sectors.

\section{Declaration of competing interest}

The authors declared that they have no conflicts of interest.

\section{Acknowledgment}

We would like to thank all study participants, data collectors, supervisors, and all health workers of governmental and private health institutions in Dessie town for their cooperation.

\section{References}

1 World health organization(WHO). Birth Defects Surveillance: Atlas of Selected Congenital Anomalies. 2014:1-28.

2 World health organization(WHO). Congenital anomalies, 1-7 Available from: htt ps://www.who.int/news-room/fact-sheets/detail/congenital-anomalies. ; 2016.

3 Egbe A, Uppu S, Lee S, Stroustrup A, Ho D, Srivastava S. Congenital malformations in the newborn population: a population study and analysis of the effect of sex and prematurity. Pediatr Neonatol. 2015;56(1):25-30. https://doi.org/10.1016/j. pedneo.2014.03.010. Available from:.

4 Toxværd ME, Garne E. Epidemiology of multiple congenital anomalies before and after implementation of a nationwide prenatal screening program in Denmark. Front Pediatr. 2021;9:35. https://doi.org/10.3389/fped.2021.614864.

5 Adane F, Afework M, Seyoum G, Gebrie A. Prevalence and associated factors of birth defects among newborns in sub-Saharan african countries: a systematic review and meta-analysis. Pan Afr Med J. 2020;36:1-22.

6 Kishimba RS, Mpembeni R, Mghamba JM, Goodman D, Valencia D. Birth prevalence of selected external structural birth defects at four hospitals in Dar es Salaam, Tanzania, 2011-2012. J Glob Health. 2015;5(2):1-6.

7 Sachdeva S, Nanda S, Bhalla K, Sachdeva R. Gross congenital malformation at birth in a government hospital. Indian J Publ Health. 2014;58(1):54-56.

8 Alanazi AFR, Naser AY, Pakan P, et al. Trends of hospital admissions due to congenital anomalies in England and Wales between 1999 and 2019: an ecological study. Int J Environ Res Publ Health. 2021;18(22):11808. https://doi.org/10.3390/ ijerph182211808.

9 World health organization(WHO). series technical report. The Selection and Use of Essential Medicines. 2015. 2012:1, 268.

10 Scheel DP. Zika virus and microcephaly: why is this situation a PHEIC? Lancet. 2016; 387:19-20. https://doi.org/10.1016/S0140-6736.(16)00320-2.

11 Aliyu LD. Fetal Congenital Anomalies in Africa: Diagnostic and Management Challenges. Intech Open; 2021:13. https://doi.org/10.1016/j.colsurfa.2011.12.014. http://dx. doi.org/10.1039/C7RA00172J\%0A. Available from: https://www.intechopen.co $\mathrm{m} /$ books/advanced-biometric-technologies/liveness-detection-in-biometrics\%0A.

12 Postoev VA, Nieboer E, Grjibovski AM, Odland JØ. Prevalence of birth defects in an Arctic Russian setting from 1973 to 2011: a register-based study. Reprod Health. 2015;12(1):4-11.

13 El Koumi MA, Al Banna EA, Lebda I. Pattern of congenital anomalies in newborn:a hospital-based study. Pediatr Rep. 2013;5(1):20-23.

14 Taye M, Afework M, Fantaye W, Diro E, Worku A. Congenital anomalies prevalence in Addis Ababa and the Amhara region, Ethiopia: a descriptive cross-sectional study. BMC Pediatr. 2019;19(1):1-11.

15 Verma RP. Evaluation and risk assessment of congenital anomalies in neonates. Children. 2021;8(10):862. https://doi.org/10.3390/children8100862.

16 Kishimba RS, Mpembeni R, Mghamba J. Factors associated with major structural birth defects among newborns delivered at Muhimbili national hospital and municipal hospitals in Dar Es Salaam, Tanzania 2011-2012. Pan Afr Med J. 2015;20: $1-7$.

17 Martinelli M, Palmieri A, Carinci F, Scapoli L. Non-syndromic cleft palate: an overview on human genetic and environmental risk factors. Front Cell Dev Biol. 2020; 8:592271.

18 Alborz A. Environmental characteristics and prevalence of birth defects among children in post-war Iraq: implications for policies on rebuilding the Iraqi education system. Med Conflict Surviv. 2013;29(1):26-44.

19 Czeizel AE, Dudás I, Vereczkey A, Bánhidy F. Folate deficiency and folic acid supplementation: the prevention of neural-tube defects and congenital heart defects. Nutrients. 2013;5(11):4760-4775.

20 Shannon GD, Alberg C, Nacul L, Pashayan N. Preconception healthcare and congenital disorders: systematic review of the effectiveness of preconception care programs in the prevention of congenital disorders. Matern Child Health J. 2014;18 (6):1354-1379.

21 Pleş L, Hamoud BH, Dimitriu MCT, et al. Psycho-emotional impact of anomaly ultrasound scan in Romanian pregnant women. Healthcare. 2021;9(11):1415. https://doi.org/10.3390/healthcare9111415.

22 Taye M, Afework M, Fantaye W, Diro E, Worku A. Magnitude of birth defects in central and northwest Ethiopia from 2010-2014: a descriptive retrospective study. PLoS One. 2016;11(10):1-12.

23 Adane F, Seyoum G. Prevalence and associated factors of birth defects among newborns at referral hospitals in Northwest Ethiopia. Ethiop J Health Dev. 2018;32 (3).

24 The Federal Democratic Republic of Ethiopia, ministry of health. National Newborn and Child Survival Strategy Document Brief Summary 2015/16-2019/20. 2015.

25 Bello AI, Acquah AA, Quartey JNA, Hughton A. Knowledge of pregnant women about birth defects. BMC Pregnancy Childbirth. 2013;13.

26 Silva J De, Amarasena S, Jayaratne K, Perera B. Correlates of knowledge on birth defects and associated factors among antenatal mothers in Galle, Sri Lanka : a crosssectional analytical study. BMC Pregnancy Childbirth. 2019;9:1-9. 
27 Ragab A, Corresponding M, Pediatric P, Cairo N. Congenital anomalies among children : knowledge and attitude of Egyptian and Saudi Mothers. J Biol Heal care. 2013;3(20):18-32.

28 El Hawary RE, Meshaal SS, Abd Elaziz DS, et al. Genetic counseling in primary immunodeficiency disorders: an emerging experience in Egypt. Mol Diagn Ther. 2017; 21(6):677-684.

29 Kanchana KTG, Youhasan P. Knowledge and attitudes on fetal anomalies among pregnant women in teaching hospital mahamodara, galle. Int J Publ Health Sci. 2018; 7(4):231.

30 Naregal P, Salunkhe J, Mohite V. Knowledge of pregnant women about congenital anomalies : a cross-sectional study at krishna hospital karad lecturer (psychiatric nursing). INDIAN J Res. 2017;5.

31 Lawal TA, Yusuf OB, Fatiregun AA. Knowledge of birth defects among nursing mothers in a developing country. Afr Health Sci. 2015;15(1):180-187.
32 Abou Faddan H, Ismail T. Awareness of married adults about congenital anomalies in a rural village. Assiut. J High Inst Public Heal. 2018;48(2):97-106.

33 Masoumeh P, Vahid K, Samira K, Hamid A, Khosheh K. Knowledge of pregnant women about congenital anomalies: a cross-sectional study in the north of Iran. Indian J Heal Sci. 2015;8(1):41.

34 Shudura E, Yoseph A, Tamiso A. Utilization and predictors of maternal health care services among women of reproductive age in hawassa University health and demographic surveillance system site, south Ethiopia: a cross-sectional study. Adv Public Heal. 2020:1-10, 2020.

35 Bobo FT, Yesuf EA, Woldie M. Inequities in the utilization of reproductive and maternal health services in Ethiopia. Int J Equity Health. 2017;16(1):1-8.

36 Yuan F, Qian D, Huang C, et al. Analysis of awareness of health knowledge among rural residents in Western China. BMC Publ Health. 2015;15(1):1-8. 